\title{
NOVEDADES EDITORIALES
}

Amitav Acharya (ed.), Why Govern? Rethinking Demand and Progress in Global Governance, Cambridge University Press, 2016, 350 pp.

El sistema de cooperación internacional, construido a partir de instituciones como Naciones Unidas después de la Segunda Guerra Mundial, se enfrenta a nuevos retos que parecen superarlo. Por un lado, la globalización causa problemas que las instituciones no resuelven, cada vez más graves, porque no se actúa ante ellos, como la crisis de refugiados, el cambio climático, los ciberataques, los abusos en derechos humanos. Por otro, el mundo se ha vuelto multipolar por el ascenso de economías como las de China, India o Brasil y con la injerencia cada vez más poderosa de empresas, organizaciones de la sociedad civil y otros actores no estatales, que ponen en jaque la estabilidad del sistema. En estas circunstancias, ¿cómo será posible una gobernanza global efectiva? En este libro, internacionalistas de todo el mundo dan respuesta a los distintos problemas contemporáneos en lo que atañe a las relaciones internacionales, ofreciendo alternativas de solución y de una nueva configuración de la gobernanza global.

Nancy Bermeo y Deborah J. Yashar (eds.), Parties, Movements, and Democracy in the Developing World, Cambridge University Press, 2017, $242 \mathrm{pp}$.

Tradicionalmente, teóricos de la modernización interpretaron la transición y la supervivencia de la democracia en países en vías de desarrollo como dependientes de condiciones materiales, tales como el tamaño del PIB, de la pobreza y de la desigualdad. Sin embargo, hay democracias que no crecen o que 
son pobres y desiguales o que sobreviven y prosperan. Este libro argumenta que los partidos políticos y los movimientos sociales permiten que esto suceda. El cambio democrático puede ocurrir a pesar del desarrollo económico, especialmente en sociedades con legados históricos de regímenes autoritarios que dan lugar a organizaciones que toman decisiones basadas en estas experiencias y que terminan por configurar un sistema de partidos y una nueva trayectoria para el régimen. Los capítulos que estudian casos en la India, Sudeste de Asia, América Latina, África Subsahariana y Medio Oriente son prueba del éxito de la democracia por la organización de colectividades que lideran el proceso de cambio de régimen.

Adeed Dawisha, Arab Nationalism in the Twentieth Century: From Triumph to Despair, Princeton University Press, 2016, 368 pp.

La situación contemporánea de Medio Oriente nos constriñe a observar el nacionalismo árabe como la fuente de muchos de los problemas de la región. Esta perspectiva nos impide pensar en el nacionalismo árabe durante sus años de esplendor, en los cuales reivindicó la unión de países completos, su soberanía y su independencia. El nacionalismo árabe comenzó a tener éxito tras la derrota del Imperio otomano luego de la Primera Guerra Mundial y alcanzó su auge con el liderazgo carismático de Gamal 'Abd al-Nasir en Egipto, durante los años cincuenta y sesenta. No obstante los éxitos de la unión entre Egipto y Siria y la revolución nacionalista iraquí, el nacionalismo árabe caería en desprestigio a partir de la Guerra de los Seis Días con Israel, en 1967. Dawisha narra este periodo del florecimiento del nacionalismo árabe e incluye un capítulo final que reflexiona sobre la influencia de esta historia en las ideas nacionalistas árabes contemporáneas del Medio Oriente. 
Barry Eichengreen, Hall of Mirrors. The Great Depression, the Great Recession and the Uses-and Misuses of History, Oxford University Press, 2016, 520 pp.

El nuevo libro del historiador económico Barry Eichengreen nos presenta la historia comparada y conectada de las dos crisis financieras del último siglo: la Gran Depresión de 1929 y la Gran Recesión de 2008. Ambas ocurrieron en condiciones similares: expansión de créditos, dudosas prácticas bancarias y un sistema financiero internacional frágil. Con las lecciones de 1929, los políticos de Estados Unidos tomaron decisiones que evitaron el colapso financiero y la depresión económica en los años treinta. Sin embargo, y de la misma manera que en esa década, el desempleo, la desigualdad y la pobreza aumentaron. ¿Por qué los políticos no dieron una mejor respuesta a estos problemas? La falta de medidas que incentivaran el gasto, reactivando así la economía, y la adopción prematura de políticas económicas normales antes que las condiciones fueran propicias, terminaron por perjudicar a los países más endeudados en Europa, donde la recesión continúa, y a la economía de Estados Unidos, donde la recuperación ha sido lenta. El producto final de estas políticas ha sido protestar en contra de políticos, bancos centrales y gobiernos que han fallado en resolver los problemas económicos de sus sociedades.

John Ferejohn y Frances McCall Rosenbluth, Forged Through Fire. War, Peace, and the Democratic Bargain, Nueva York, Liveright Publishing Corporation, 2016, 480 pp.

Ferejohn y Rosenbluth presentan una provocadora hipótesis producto de su investigación sobre la formación del Estado moderno en Occidente: la aparición y consolidación de la democracia depende de la guerra. De la Antigua Grecia a los Estados Unidos de la Segunda Guerra Mundial, los gobiernos han movilizado ejércitos para defender su territorio y soberanía. Estos ejércitos se componen de soldados que se convierten en ciudadanos, cuando intercambian su participación en 
batalla por derechos políticos. Cuando la élite no necesita de los ciudadanos para defenderse de alguna amenaza externa, el vínculo de representación se suprime y con él también la democracia. Las implicaciones de sus conclusiones son relevantes para la actualidad, tiempo en que las batallas entre ejércitos se sustituyen con tecnologías remotas que no necesitan la movilización masiva de personas.

Corey D. Fields, Black Elephants in the Room. The Unexpected Politics of African American Republicans, University of California Press, 2016, 296 pp.

Por la radicalización del discurso del Partido Republicano y la reaparición del cribaje racial como fundamentos para entender la vida política contemporánea de Estados Unidos, se suele interpretar como una contradicción encontrar a ciudadanos afroamericanos como partidarios del GOP. El autor de este libro demuestra, a la luz del trabajo etnográfico y del análisis de opinión pública, que esta intuición es una simplificación. Los afroamericanos, en el Partido Republicano, son ciudadanos conscientes y autodefinidos según sus términos raciales, que piensan sobre asuntos económicos y sociales en estas líneas. Su pensamiento político e ideológico busca reconciliar los elementos clásicos del conservadurismo estadounidense (gobierno limitado, pocos impuestos y conservadurismo social) con su identidad racial, creando un pensamiento complejo que los hace divergir tanto de nuestra expectativa de un republicano como de un afroamericano.

Justin Gest, The New Minority. White Working Class Politics in an Age of Immigration and Inequality, Oxford University Press, 2016, 268 pp.

El sorpresivo triunfo de Donald Trump en Estados Unidos ha suscitado un intenso debate sobre el papel de la clase trabajadora blanca en ese país. La explicación más difundida argumenta que este grupo demográfico fue ignorado por los partidos políticos en el gobierno y sus necesidades, silenciadas. 
Este proceso fue retroalimentado por una creciente desigualdad económica que lo empobreció. Los "clasemedieros" de antaño ahora se encuentran en las posturas más radicales de la política y en movimientos nativistas y de derecha cuando hace unas décadas eran quienes llevaban la política hacia el centro. ¿Qué propició esta situación? ¿Qué hace que la clase blanca trabajadora se identifique como una nueva minoría? El autor da respuesta a estas preguntas mediante conversaciones con habitantes de ciudades industriales en Estados Unidos e Inglaterra (donde el fenómeno también ha ocurrido) para mostrar los motivos de su comportamiento y actitudes políticas. Su argumento principal es que la tensión en los vestigios del poder, que la clase blanca trabajadora había comparado con la percepción de la pérdida de su poder, ha llevado a este fenómeno de radicalización.

Stephan Haggard y Robert R. Kaufman, Dictators and Democrats: Masses, Elites, and Regime Change, Princeton University Press, 2016, 424 pp.

Desde los años ochenta del siglo pasado, países en vías de desarrollo, desde América Latina hasta la Europa postcomunista, han transitado a regímenes democráticos. En retrospectiva, ha habido una varianza por considerar en estos procesos de transición. Algunos países han logrado consolidarse como exitosas democracias, mientras que otros han experimentado algún tipo de regresión autoritaria. ¿Qué explica la diferencia en estas trayectorias? Haciendo un análisis cuantitativo y cualitativo de más de cien casos de transiciones a la democracia, los autores muestran que el éxito de ésta recae en las instituciones existentes y la capacidad que tenga el público de actuar colectivamente. Así, las democracias que surgen a partir de movilizaciones en masa propician la aparición de instituciones que evitan la reversión autoritaria, a la inversa de aquellas que lo hacen a partir de negociaciones entre élites. 
Christopher Herrick, Zheya Gai y Saurain Subramaniam, China's Peaceful Rise. Perceptions, Policy and Misperceptions, Manchester University Press, 2016, 416 pp.

El ascenso de China es uno de los temas más tratados en la bibliografía especializada contemporánea sobre relaciones internacionales. De ésta no poca se concentra en el creciente poderío militar chino, para señalarla como una potencia militarista y una amenaza a la seguridad internacional. Este libro cuestiona tal premisa, para tratar la "cuestión china" desde otra perspectiva ¿Es posible que China se convierta en una superpotencia de forma pacífica? A partir de teorías constructivistas de relaciones internacionales, los autores argumentan que la posibilidad de ascenso pacífico dependerá de las percepciones que se tengan sobre el desarrollo chino, especialmente en lo que toca al poder y a la economía. Estas percepciones se forman a la luz de consideraciones de poder e intereses económicos basadas en el legado histórico de China y su comportamiento en foros internacionales, así como en su relación con otros países. La reflexión del libro es que las predicciones para China y su relación con el sistema internacional pueden no ser tan oscuras como los realistas argumentan, pero tampoco tan optimistas como espera el gobierno chino.

Kosuke Imai, Quantitative Social Science: An Introduction, Princeton University Press, 2017, 432 pp.

Kosuke Imai, profesor de Ciencia Política en la Universidad de Princeton y en la de Tokio, ofrece en este libro una introducción de vanguardia sobre metodología de investigación cuantitativa para las ciencias sociales. Con esto, el autor desea tender un puente entre la enseñanza rigurosa de métodos estadísticos y la aplicación de éstos a la investigación de temas que ocupan a los estudiantes de ciencias sociales. El libro, complementado con materiales en línea, busca hacer que el lector se comprometa a ejecutar la teoría con ejemplos empíricos tomados de investigaciones 
originales y relevantes en la bibliografía especializada sobre investigación social cuantitativa.

Ignacio Marván Laborde, Cómo hicieron la Constitución de 1917, México, Fondo de Cultura Económica, 2017, 311 pp.

La conmemoración del centenario de la Constitución Mexicana de 1917 atrajo la atención de editoriales y autores de distintas disciplinas. Ignacio Marván se aleja del análisis del contenido constitucional para realizar una historia politológica de la redacción de nuestra Carta Magna. Para ello, estudia el proceso que permitió la instalación del Congreso Constituyente, los actores que participaron en él, sus planes y los incentivos políticos que terminaron por suscribirse en la Constitución. El autor analiza en especial las continuidades de la constitución centenaria con su antecesora y la aparente contradicción histórica de apoderar al Ejecutivo, luego de una revolución nacida con el propósito de limitarlo.

Jason Seawright, Multi-method Social Science. Combining Qualitative and Quantitative Tools, Cambridge University Press, 2016, 246 pp.

La bibliografía sobre metodología de investigación para las ciencias sociales tiende a asumir una clara postura ante el uso exclusivo de métodos cuantitativos o cualitativos, dejando poco lugar para la complementariedad de ambos recursos. Este libro propone una guía sistemática para realizar investigaciones que concilien métodos cualitativos y cuantitativos en un marco integrativo multimetódico. El autor propone formas innovadoras en que los métodos econométricos se complementan con estrategias como el estudio de caso o la política comparada para pensar con mayor profundidad sobre la selección de observaciones, la validez de experimentos naturales y el rigor de las conclusiones derivadas de los métodos de inferencia causal. La intención del trabajo es clara: tomar lo útil de cada estrategia de investigación para generar conclusiones robustas y apegadas a los fenómenos reales estudiados por las ciencias sociales. 
Jeffrey D. Sachs, Building the New American Economy. Smart, Fair and Sustainable, Columbia University Press, 2017, 152 pp.

El nuevo libro de Sachs ofrece una idea de consenso para reconstruir la economía de Estados Unidos: el desarrollo sostenible. A la inversa de las ideas económicas predominantes que tienen por prioridad el crecimiento económico sobre el de la desigualdad, el desarrollo sostenible considera circunstancias sociales, económicas y medioambientales en la ejecución de políticas públicas. Con este marco teórico, el autor analiza los problemas contemporáneos de la economía estadunidense (infraestructura, apertura comercial, política energética, tamaño del gobierno, deuda y desigualdad), para proponer políticas que puedan resolverlos. El mensaje del libro es optimista y refleja la convicción de Sachs sobre la posibilidad de encontrar un progreso económico justo y sostenible.

Colaboración de Julio S. Solís Arce 